\title{
Peri-partum posture and behaviour of gilts and the location of their piglets in lines selected for components of efficient lean growth
}

\author{
C.P. McPhee, J.C. Kerr ${ }^{*}$ and N.D. Cameron** \\ Corresp. author,Animal Research Institute, LMB 4, Moorooka, Q 4105, Australia, \\ Telephone 61733629417, Fax 61733629429, E mail mcpheec@dpi.qld.gov.au \\ ${ }^{*}$ PPL Therapeutics, Roslin, Midlothian, EH25 9PP, Scotland \\ ${ }^{* *}$ Roslin Institute (Edinburgh), Roslin, Midlothian, EH25 9PS, Scotland
}

\begin{abstract}
The proportions of time that gilts expressed defined posture and behaviour traits and the locations of their piglets were determined from video recordings of observations made at 5 min intervals in the period extending from $2 \mathrm{hr}$ pre-farrowing to $2 \mathrm{hr}$ post-farrowing. The 137 gilts studied were from four pairs of Large White lines which had responded to divergent (high and low) selection for either daily food intake (DFI), lean food conversion efficiency (LFC), lean growth rate on ad libitum feeding (LGA) or lean growth rate on restricted feeding (LGS).

Almost all the significant $(P<.05)$ changes occurred in the LGS pair of lines. In the prefarrowing period, relative to the low LGS gilts, high LGS gilts spent more time lying on their sides (0.92 v. 0.69), and less time in the upright postures of standing, sitting or lying on their bellies (0.08 v. 0.33$)$ and engaging in nesting behaviour (0.02 v. 0.10). During farrowing high LGS gilts again lay on their sides more often than low LGS gilts (0.96 v. 0.80$)$ and were upright less often (0.04 v. 0.20). High LGS gilts changed posture less often than low LGS gilts (0.05 v. 0.31$)$ but were more alert $(0.79$ v. 0.61$)$. High LGS piglets were seen less at their mother's head, back and vulva or at the creep than low LGS piglets $(0.06 \mathrm{v}$. 0.15$)$. There were no differences between lines post-farrowing, almost all gilts lying on their sides with their piglets at the udder. Divergent selection for components of efficient lean growth rate on ad libitum feeding was not associated with changes in gilt behaviour and posture or in piglet location but selection for high lean growth on restricted feeding appeared to reduce the gilt's physical activity around farrowing with possible benefits for her welfare and that of her piglets. Keywords: Gilts; Lean growth; Farrowing behaviour; Piglet-location; Selection
\end{abstract}




\section{Introduction}

Interest has been raised over possible changes in the behaviour of livestock selected for high genetic merit for production traits which could affect their ability to thrive in intensive production environments (Mills, Beilharz and Hocking, 1997). If artificial farrowing environments fail to satisfy the welfare needs of the peri-parturient sow of these modern genotypes, reproductive traits could be adversely affected leading to economic loss. Studies of pig genotypes for behavioural differences of sows around farrowing have usually compared breeds which differ markedly in performance of production traits, such as efficiency of lean growth, and litter productivity. Typical studies are those of Meunier-Salaün et al., (1991), Wattanakul et al., (1997) and Sinclair et al., (1998), with Large White and Meishan or Meishan synthetic pigs. The specific behavioural traits examined in these studies reflect the welfare of the sow and her piglets and have also been used widely to test modifications to artificial farrowing environments (e.g. straw versus no straw by Cronin and Smith, 1992). One deficiency in the breed comparisons of peri-parturient behaviour of sows is that they generally lack a clear definition of the development processes which have led to the genetic differences in productivity between the breeds.

Selection for different components of efficient lean growth rate has generated a set of well-defined genetic lines (Cameron, 1994). This study examines if the different selection strategies in these lines have affected the postures and behaviours of gilts and their piglets in a period commencing two hours before and lasting until two hours after farrowing. It also provides an indication of the effect of the strategies on general physical activity, an important component of energy expenditure in pigs (Henken et al., 1991).

\section{Materials and Methods}

\subsection{Animals}

Observations were made on Large White gilts and their offspring from four selection groups, each with a high and a low selection line. The selection criteria for the groups were daily food intake (DFI), lean food conversion (LFC) and lean growth rate (LGA), all measured on ad-libitum feeding, and lean growth rate on restricted feeding (LGS). Selection in all lines had been practised for seven generations. All lines responded to their selection criteria in the 
directions intended. Responses in the ad libitum fed lines (LGA, LFC, DFI) are described by Cameron and Curran, (1994) and in the restricted fed lines (LGS) by Cameron and Curran, 1995.

The numbers of gilts on which posture and behaviour observations were made within the high and low selection lines of the groups were DFI (21 and 19), LFC (17 and 22), LGA (10 and 12) and LGS (23 and 13). The rearing and mating procedures for the gilts are fully described by Cameron et al., (1999). During gestation, four gilts were housed in the same pen and fed in individual stalls twice-daily. One week before farrowing, gilts were moved to farrowing crates. Due to a farm-management system which used batch-farrowing, gilts of the high and low lines from the same selection group (e.g. DFI) farrowed at the same time with a 6 wk interval between groups. This meant that statistically valid comparisons could only be made between the high and low lines of the same group.

The farrowing house consisted of ten temperature-controlled $\left(20^{\circ} \mathrm{C}\right)$ rooms, each with eight farrowing crates (Beacon, UK) which measured $1.7 \mathrm{~m}$ wide $\times 2.0 \mathrm{~m}$ long with a $0.6 \mathrm{~m}$ wide sow-stall centred in parallel with the crate sides. The floor at the front of the farrowing crate was solid with a steel mesh at the rear. The piglet creep box was situated at the front on one side of the farrowing crate and was heated by a 250 watt bulb turned on one week prior to farrowing. Monochrome video cameras (Panasonic WVBP100) with $2.1 \mathrm{~mm}$ wide-angle lenses (Panasonic WVLA210C3) were mounted at the front of each farrowing crate and were switched on $12 \mathrm{hr}$ before the expected time of the first farrowing of the batch of gilts. The video cameras were connected to a time lapse video recorder (Panasonic AG6124) through a digital field switcher (Panasonic WJFS20), which permitted simultaneous recordings from eight video cameras and which date-stamped all video images.

The posture and behaviour traits and piglet locations described in Table 1, were defined prior to interpretation of the video images, using recognised categories (Jarvis et al., 1999). Of those gilts for which recordings were available from two hours before to two hours after farrowing the postures and behaviours were recorded every five minutes. Observations were also made at five minute intervals of the locations of each gilt's piglets on and around their mothers. All observations were transcribed by one person (JCK) from the video images using the interval recording technique described by Jensen et al., (1986). To minimise systematic bias in assessment of posture and behaviour of gilts and location of their piglets in the 
different selection lines, each gilt was allocated a random number prior to interpretation of the video images and the gilts' video images were assessed in numerical order.

\subsection{Statistical analysis.}

From the total number of observations of posture and behaviour traits, those made on each gilt at five minute intervals from two hours before farrowing until two hours after the birth of her last piglet were used in this study. Counts of piglets were made at the different locations during and post-farrowing. Analyses were carried out separately for the farrowing and the pre and post-farrowing periods. Posture and behaviour observations were binomially distributed with number of trials equal to the number of five minute observations within each period. The number of piglets observed for each location, with values ranging from zero to the total number viewed at all locations was also treated as a binomially distributed trait.

For each period the data were analysed using the procedure of Schall, (1991) in a generalised linear mixed model (Genstat 5 Committee, 1997). The model had binomial errors and a logit function was used to transform the posture, behaviour and piglet-minute scores into liabilities. The analysis fitted effects for each selection line $x$ time interval with the gilt effect included as a normally distributed random term. The statistical significance of differences between means was evaluated on the logit scale and mean values were back transformed to the proportionate observation of each gilt posture and behaviour and piglet location. The relationship between the predicted score $(\hat{p})$ and the logit score $(\mathbf{x})$ is $\hat{p}=\frac{e^{x}}{1+e^{x}}$.

\section{Results}

\subsection{Postures}


Proportions of time spent by gilts in different postures over the whole observation period are given in Table 1. Lying was by far the most frequent posture adopted, gilts showing an increasing preference with time for lying on their sides and a decreasing preference for adopting the upright postures of lying on their bellies, standing or sitting. In Tables 2 and 3 the fitted mean proportions of gilts seen lying on their sides or adopting the upright postures in the three observation periods are given for each line. The only significant difference between the high and the low lines of any group occurred in LGS lines. For pre-farrowing, gilts of the high LGS line lay on their sides more often than gilts of the low LGS line. In Figure 1 are plotted changes in the proportions of LGS gilts either lying on their sides or adopting an upright posture through the pre-farrowing period. Whilst high LGS gilts maintained a constantly high level of the lying posture and a low level of the upright posture throughout, low LGS gilts tended to delay exchanging the upright posture for the lying posture until close to farrowing. The trend for gilts of the high LGS line to spend a higher proportion of their time lying on their sides than low LGS gilts continued during farrowing but disappeared during the post-farrowing period (Table 2). The converse was true of standing, sitting and belly lying, with the high LGS gilts adopting these upright postures to a lesser degree than low LGS gilts before farrowing (0.08 v. 0.33)(logits : -2.45 v. -0.70 , s.e.d. 0.40$)$ and during farrowing (0.04 v. 0.20)(logits : 3.22 v. -1.36 , s.e.d. 0.47$)$.

\subsection{Behaviours}

Values in Table 1 show alertness and restlessness to be the predominant gilt behaviours throughout the whole peri-partum observation period with restlessness giving place to alertness with the passage of time from pre to post-farrowing. Sleeping and nesting behaviour were almost exclusively confined to pre-farrowing and frequent posture changing to the farrowing period. In Table 3 are given selection line means of alertness behaviour for the three observation periods. The only significant differences between directions of selection occurred in the LFC and LGS groups, the high lines of which were more alert than the low line during farrowing. Table 4 shows the line means for pre-farrowing nesting behaviour and 
posture changing during and post-farrowing. Again, the only significant line differences occurred in the LGS group. Compared with the low line, the high line performed less nesting behaviour pre-farrowing (Figure 2) and had fewer postural changes during farrowing. There were no line differences in any behaviours in the post-farrowing period.

\subsection{Piglet locations}

The spatial distribution of piglets around their mothers during and post-farrowing is described by the proportions of piglet in different locations in Table 1. Almost all piglets were seen at the udder, particularly in the post-farrowing period. Of the remainder, a higher proportion were viewed around the gilts' feet and vulva during farrowing than post-farrowing. Line means of proportions are shown in Table 5. The only significant effect of direction of selection was again recorded in the LGS group. Compared with the low line, high line piglets had a higher occupancy of the head and lower occupancies of the back and creep locations during farrowing. Overall, piglet sightings at these locations were low (0.08). In the postfarrowing period there were no significant differences between lines in the spatial distribution of piglets.

\subsection{Litter size and parturition length}

The mean number of piglets born alive per litter was $9.7 \pm 0.3$ and the mean parturition length (time interval between the births of the first and last piglet) was $132 \pm 13 \mathrm{~min}$. There were no significant differences between selection groups or lines for either trait.

\section{Discussion}

The selection criteria of the four selection groups focused only on the performance test traits of growth rate, ultrasonic backfat depth and daily food intake (Cameron, 1994) with no direct selection pressure on reproduction or behaviour traits. The nutritional inputs, animal 
husbandry practices and environment associated with the selection experiment did not change throughout the period of selection. The divergent selection lines within each selection group were farrowed and tested simultaneously, so that responses to selection were of a genetic origin and not a result of "environmental" changes. If there were genetic relationships between traits in the selection criteria and non-production traits, then associated responses in the non-production traits would be expected to occur.

The proportions of time spent lying (0.8), standing (0.1) or sitting (0.1) in the pre-farrowing period of this study were similar to those reported by Cronin et al. (1993) in the $8 \mathrm{hr}$ period prior to farrowing, which were $0.7,0.2$ and 0.1 , respectively. Therefore, conclusions regarding the posture and behaviour of gilts from the selection lines drawn from the relatively short period of pre-farrowing observation in the current study are expected to be consistent with those obtained with a longer period of observation. Trends in lying posture in this period suggested that the high LGS line gilts were either not inclined to nest or had completed nesting behaviour and adopted the lying posture in preparation for farrowing earlier than low LGS line gilts. Thodberg et al., (1999) reported an average interval of $1.3 \mathrm{hr}$ from the termination of nesting behaviour to the onset of parturition, similar to that of the low LGS gilts. They also found favourable effects on maternal behaviour, including decreased crushing of piglets, with increased separation in time from nest building to farrowing. Cronin et al. (1993) reported that the proportion of time in a lying posture during $6 \mathrm{hr}$ post-farrowing was at least 0.9 , such that there may be possible benefits in mothering ability during the immediate postfarrowing period for sows which adopt the lying posture earlier in the pre-farrowing period. This gives the impression that high LGS gilts have an advantage over low LGS gilts in maternal behaviour. This impression is reinforced by observations during farrowing when gilts of the high LGS line lay on their sides for longer than low LGS gilts. This apparent genetic difference in lying posture is supported by Sinclair et al. (1998) who found that sows of a synthetic line which included genes of the Meishan, spent more time lying on their sides with their udders exposed than Large White sows. The lower levels of posture changing and nesting and higher levels of alertness in high LGS than in low LGS gilts are also consistent with the general impression of better adaptation to the housing environment in the high than in the low line. Using levels of cortisol as an indicator of stress, Barnett et al. (1988) inferred 
that pregnant sows of a Large White $X$ Landrace synthetic line selected in a not dissimilar way to high LGS were better adapted to intensive housing than sows of an unselected line.

The upright postures of lying on the belly, standing and sitting followed by lying have been found to be major contributors to deaths of piglets through crushing (Edwards and Malkin, 1986). Morrow-Tesch and McGlone (1990) reported variation between sows in their inclination to adopt a sitting posture and those that did so had three times the rate of piglet crushing as those that did not. In the present study, gilts from the high LGS line spent significantly less time in these upright postures during farrowing than gilts from the low LGS line. This apparent genetic variation in these postures is consistent with the finding by McGlone et al. (1991) of a moderate heritability estimate for sitting behaviour in pigs. The spatial distribution of the piglets is also likely to have a bearing on their risk of being crushed when their mothers change posture. Piglets seem at greatest risk from crushing when located near their mother's feet and vulva, particularly when she is standing or sitting, and at least risk when near her head or udder, circumstances likely to favour the survival of high LGS piglets. It is surprising therefore that they were found by Kerr and Cameron (1995) to have a slightly higher pre-weaning mortality than low LGS piglets although the contribution of crushing to this mortality was not determined. Much of the differences in the spatial distribution of the high and low LGS piglets can be explained by the line differences in postures adopted by their mothers.

Parturition length has been used as an indicator of stress during farrowing. Sows which are susceptible to stress prolong their parturitions (Lawrence et al., 1992) which increases the risk of death of piglets through anoxia. The introduction of sawdust to alleviate the stress of a crate farrowing environment by Cronin et al. (1993) was found to reduce parturition length from 201 min to 159 min The mean parturition length of the lines in the present study, 132 min, was close to the 136 min recorded by Cronin et al. (1994) and was of the same order as the 150 min quoted by Jackson (1976) for the average sow. The absence of significant difference in parturition length between the lines of this study which varied so much in production traits, implies a lack of covariation between these traits and susceptibility to the stress of farrowing in an intensive housing environment.

Postural and behavioural differences between high and low LGS gilts indicated the former to be less physically active than the latter around farrowing. If this is characteristic of all ages 
and both sexes, it may indicate lower energy requirements for maintenance for high LGS, as the amount of maintenance heat production has been shown to be positively associated with activity by Henken et al. (1991). The selection criteria for the high LGS selection line emphasised high growth rate, with animals performance tested on a restricted feeding regime $(0.75 \mathrm{~g} / \mathrm{g}$ of daily ad-libitum food intake). Therefore, there was indirect selection for more efficient use of nutrients since the daily ration during performance test was fixed. One way this could occur is through a reduction in that portion lost in maintenance heat production through physical activity. A higher proportion of nutrients could then be available for at least part of the increased growth found in the high LGS line (Cameron et al., 1994). When the LGS lines were compared on ad libitum feeding, no change in food intake accompanied the selection responses in growth rate in the LGS lines (Cameron and Curran, 1995). On the other hand, in the DFI, LGA and LFC lines, performance tested and selected on ad libitum feeding, changes in food intake did occur (Cameron and Curran, 1994) and these may have contributed to responses in the selection criteria through changes in nutrient supply.

In conclusion, almost all of the posture and behaviour differences between the high and low lines occurred in the LGS selection group before the end of parturition. Relative to the low line LGS gilts, those in the high line had an increased tendency toward lying on the side in an alert state and a reduced tendency toward adopting an upright posture or changing posture. After farrowing, line differences were suppressed as almost all gilts lay on their sides with their piglets at the udder. Evidently selection strategies for components of efficient lean growth rate, based on ad-libitum feeding, can focus on production traits without expecting correlated responses in pre-farrowing posture and behaviour traits. On the other hand, selection for high lean growth on restricted feeding appears to reduce physical activity and this may be beneficial to the welfare of the gilt and that of her piglets and save energy for increased growth. 


\section{Acknowledgements}

The authors thank S. Jarvis for discussions on defining posture and behaviour traits and

R. Fenty for management of animals in the farrowing house. The U.K. Ministry of Agriculture, Fisheries and Food funded the study.

\section{References}

Barnett, J. L., Hemsworth, P.H., Cronin, G. M., Winfield, C. G., McCallum, T. H. and Newman, E. A. 1988. The effects of genotype on physiological and behavioural responses related to the welfare of pregnant pigs. Appl. Anim. Behav. Sci. 20:287-296.

Cameron, N. D. 1994. Selection for components of efficient lean growth rate in pigs. 1. Selection pressure applied and direct responses in a Large White herd. Anim. Prod. 59: 251-262.

Cameron, N.D. and Curran, M.K. 1994. Selection for components of efficient lean growth rate in pigs. 4. Genetic and phenotypic parameter estimates and correlated responses in performance test traits with ad-libitum feeding. Anim. Prod. 59: 281-291.

Cameron, N.D., Curran, M.K. and Kerr, J. C. 1994. Selection for components of efficient lean growth rate in pigs. 3. Responses to selection with a restricted feeding regime. Anim. Prod. 59: 271-279.

Cameron, N.D. and Curran, M.K. 1995. Responses in carcass composition to divergent selection for components of efficient lean growth in pigs. Anim. Sci. 61: 347-359.

Cameron, N.D., Kerr, J.C., Garth, G.B. and Sloan, R.L. 1999. Genetic and nutritional effects on age at first oestrus of gilts selected for components of efficient lean growth rate. Anim. Sci. (in press).

Cronin, G. M. and Smith, J. A. 1992. Suckling behaviour of sows in farrowing crates and straw bedded pens Appl. Anim. Behav. Sci. 33:175-189.

Cronin, G. M., Schirmer, B. N., McCallum, T. H., Smith, J. A. and Butler, K. L. 1993. The effects of providing sawdust to pre-parturient sows in farrowing crates on sow behaviour, the duration of parturition and the occurrence of intra-partum stillborn piglets. Appl. Anim. Behav. Sci. 36:301-315. 
Cronin, G. M., Smith, J. A., Hodge, F. M. and Hemsworth, P. H. 1994. The behaviour of primiparous sows around farrowing in response to restraint and straw bedding. Appl. Anim. Behav. Sci. 39: 269-280.

Edwards, S. A. and Malkin, S. J. 1986. An analysis of piglet mortality with behavioural observations. Anim. Prod. 42:470, abstr.

Genstat 5 Committee. 1997. Release 4.1 PC/Windows NT. Lawes Agricultural Trust, Rothamsted Experimental Station, UK.

Henken, A.M., van der Hel, W., Brandsma H.A. and Verstegen, M.W.A. 1991. Differences in energy metabolism and protein retention of limit-fed growing pigs of several breeds. J. Anim. Sci., 69: 1443-1453.

Jackson P. 1976. When things go wrong at farrowing. Pig Farming 24:43-47.

Jarvis, S, McLean, A., Calvert, S.K., Deans, L.A., Chirnside, J. and Lawrence, A.B. 1999. The responsiveness of sows to their piglets in relation to the length of parturition and the involvement of endogenous opioids. Appl. Anim. Behav. Sci. (in press).

Jensen, P., Algers, B. and Ekesbo, I. 1986. Methods of Sampling and Analysis of Data in Farm Animal Ethology. Birkhauser, Basel, 86 pp.

Kerr, J. C. and Cameron, N. D. 1995. Reproductive performance of pigs selected for components of efficient lean growth. Anim. Sci. 60:281-290.

Lawrence, A. B., Petherick, J. C. McLean, K. A., Gilbert, C. L., Chapman, C. and Russell, J. A. 1992. Naloxone prevents interruption of parturition and increases plasma oxytocin following environmental disturbance in parturient sows. Phys. Behav. 52:917-923.

McGlone, J. J., Akins, C. K. and Green, R. D. 1991. Genetic variation in sitting frequency and duration in pigs. Appl. Anim. Behav. Sci. 30(3/4):319-322.

Meunier-Salaün, M.C., Gort, F, Prunier, A. and Schouten, W.P.G. 1991. Behavioural patterns and progesterone, cortisol and prolactin levels around parturition in European (LargeWhite) and Chinese (Meishan) sows. Appl. Anim. Behav. Sci. 31:43-59.

Mills, A.D., Beilharz, R.G. and Hocking, P.M. 1997. Genetic selection. In: M.C. Appleby and B.O. Hughes (Editors), Animal Welfare. CAB International, Oxford, pp 219-231.

Morrow-Tesch and McGlone J. J. 1990. Productivity and behaviour of sows in level vs. sloped farrowing pens and crates. J. Anim. Sci. 68:82-87. 
Thodberg, K., Jensen, K. H., Herskin, M. S. and Jorgensen E. 1999. Influence of environmental stimuli on nest building and farrowing behaviour in domestic sows. Appl. Anim. Behav. Sci. 63:131-144.

Schall, R. 1991. Estimation in generalised linear models with random effects. Biometrika 78 : 719-727.

Sinclair A. G., Edwards, S. A., Hoste, S. and McCartney, A. 1998. Evaluation of the influence of maternal and piglet breed differences on behaviour and production of Meishan synthetic and European White breeds during lactation. Anim. Sci. 66:423-430.

Wattanakul, W., Sinclair, A.G., Stewart, A.H., Edwards, S.A. and English, P.R. 1997.

Performance and behaviour of lactating sows and piglets in crate and multisuckling systems: a study involving European White and Manor Meishan genotypes. Anim. Sci. 64: 339-349. 
Table 1

Overall proportions of postures and behaviours adopted by gilts and of piglets at different locations around farrowing.

\begin{tabular}{|c|c|c|c|c|}
\hline \multirow{3}{*}{ Gilt posture } & & \multicolumn{3}{|c|}{ Observation period } \\
\hline & & \multirow[t]{2}{*}{$\begin{array}{c}\text { Pre- } \\
\text { farrowing }\end{array}$} & \multirow[t]{2}{*}{ Farrowing } & \multirow[t]{2}{*}{$\begin{array}{l}\text { Post- } \\
\text { farrowin }\end{array}$} \\
\hline & & & & \\
\hline Standing: & at least three feet on floor & 0.10 & 0.08 & 0.01 \\
\hline Sitting & & 0.06 & 0.05 & 0.01 \\
\hline \multirow[t]{2}{*}{ Lying: } & on side with udder exposed & 0.73 & 0.82 & 0.96 \\
\hline & on belly with udder concealed & 0.10 & 0.04 & 0.01 \\
\hline \multicolumn{5}{|c|}{ Gilt behaviour } \\
\hline Alert: & aware of surroundings but lying still & 0.55 & 0.74 & 0.74 \\
\hline Sleeping: & not aware of surroundings & 0.12 & 0.02 & 0.17 \\
\hline Restless: & $\begin{array}{l}\text { generally active but not other } \\
\text { behaviours }\end{array}$ & 0.22 & 0.25 & 0.08 \\
\hline $\begin{array}{l}\text { Changing } \\
\text { postures }\end{array}$ & between five minute observations & - & 0.21 & 0.04 \\
\hline Nesting: & $\begin{array}{l}\text { chewing, biting, nosing or pawing crate } \\
\text { or floor }\end{array}$ & 0.10 & - & - \\
\hline \multicolumn{5}{|c|}{ Piglet location } \\
\hline Head: & vicinity of trough & - & 0.09 & 0.04 \\
\hline Creep & & - & 0.03 & 0.02 \\
\hline Feet: & surrounding but not at udder & - & 0.16 & 0.05 \\
\hline Back: & on opposite side to udder & - & 0.05 & 0.02 \\
\hline Vulva & & - & 0.07 & 0.03 \\
\hline Udder & & - & 0.60 & 0.85 \\
\hline
\end{tabular}


Proportions of observations of lying on the side for the four groups of selection lines. Logits in parenthesis.

\begin{tabular}{|c|c|c|c|c|c|c|}
\hline \multirow{2}{*}{$\begin{array}{l}\text { Period } \\
\text { Line }\end{array}$} & \multicolumn{2}{|c|}{ Pre-farrowing } & \multicolumn{2}{|c|}{ Farrowing } & \multicolumn{2}{|c|}{ Post-farrowing } \\
\hline & High & Low & High & Low & High & Low \\
\hline \multirow[t]{2}{*}{ DF1 } & 0.67 & 0.75 & 0.80 & 0.85 & 0.99 & 0.99 \\
\hline & $(0.72)$ & $(1.12)$ & (1.38) & (1.77) & $(5.16)$ & (4.55) \\
\hline \multirow[t]{2}{*}{ LFC } & 0.73 & 0.72 & 0.84 & 0.81 & 0.98 & 0.97 \\
\hline & $(1.02)$ & $(0.93)$ & $(1.64)$ & $(1.44)$ & $(4.17)$ & (5.35) \\
\hline \multirow[t]{2}{*}{ LGA } & 0.73 & 0.81 & 0.90 & 0.93 & 0.99 & 0.99 \\
\hline & (1.02) & $(1.46)$ & $(2.20)$ & (2.61) & $(4.27)$ & $(4.25)$ \\
\hline \multirow[t]{2}{*}{ LGS } & 0.92 * & 0.69 & 0.96 * & 0.80 & 0.99 & 0.98 \\
\hline & $(2.40)$ & $(0.69)$ & (3.19) & (1.36) & $(4.45)$ & (3.90) \\
\hline
\end{tabular}

* High-Low significant $(p<0.05)$

=Average s.e. of difference High - Low within line. 
Table 3

Proportion of observations of alert behaviour for the four groups of divergent selection lines. Logits in parenthesis.

\begin{tabular}{|c|c|c|c|c|c|c|}
\hline \multirow{2}{*}{$\begin{array}{l}\text { Period } \\
\text { Line }\end{array}$} & \multicolumn{2}{|c|}{ Pre-farrowing } & \multicolumn{2}{|c|}{ Farrowing } & \multicolumn{2}{|c|}{ Post-farrowing } \\
\hline & High & Low & High & Low & High & Low \\
\hline \multirow[t]{2}{*}{ DF1 } & 0.59 & 0.52 & 0.51 & 0.71 & 0.81 & 0.82 \\
\hline & $(0.37)$ & $(0.06)$ & $(0.06)$ & $(0.90)$ & $(1.47)$ & (1.49) \\
\hline \multirow[t]{2}{*}{ LFC } & 0.67 & 0.57 & 0.85 * & 0.68 & 0.79 & 0.78 \\
\hline & $(0.70)$ & $(0.28)$ & $(1.74)$ & $(0.75)$ & $(1.31)$ & (1.28) \\
\hline \multirow[t]{2}{*}{ LGA } & 0.51 & 0.53 & 0.72 & 0.64 & 0.87 & 0.77 \\
\hline & $(0.05)$ & $(0.11)$ & $(0.90)$ & $(0.60)$ & $(1.87)$ & (1.19) \\
\hline \multirow[t]{2}{*}{ LGS } & 0.57 & 0.50 & 0.79 * & 0.61 & 0.87 & 0.85 \\
\hline & $(0.27)$ & $(0.00)$ & (1.33) & $(0.43)$ & (1.92) & (1.74) \\
\hline s.e. of diff $=$ & & & & & & \\
\hline
\end{tabular}

High-Low significant $(p<0.05)$

=Average s.e. of difference High - Low within line. 
Table 4

Proportions of observation of pre-farrowing nesting behaviour and posture changing during and post-farrowing. Logits in parenthesis.

\begin{tabular}{|c|c|c|c|c|c|c|}
\hline Period & \multicolumn{2}{|c|}{ Pre-farrowing } & \multicolumn{2}{|c|}{ Farrowing } & \multicolumn{2}{|c|}{ Post-farrowing } \\
\hline Behaviour & \multicolumn{2}{|c|}{ Nesting } & \multicolumn{2}{|c|}{ Posture change } & \multicolumn{2}{|c|}{ Posture change } \\
\hline Line & High & Low & High & Low & High & Low \\
\hline \multirow[t]{2}{*}{ DF1 } & 0.11 & 0.06 & 0.025 & 0.14 & 0.01 & 0.01 \\
\hline & $(-2.08)$ & $(-2.79)$ & $(-1.11)$ & $(-1.78)$ & $(-4.54)$ & $(-4.34)$ \\
\hline \multirow[t]{2}{*}{ LFC } & 0.08 & 0.07 & 0.20 & 0.27 & 0.02 & 0.04 \\
\hline & $(-2.46)$ & $(-2.61)$ & $(-1.36)$ & $(-1.98)$ & $(-3.71)$ & $(-3.21)$ \\
\hline \multirow[t]{2}{*}{ LGA } & 0.11 & 0.06 & 0.14 & 0.12 & 0.01 & $<0.01$ \\
\hline & $(-2.13)$ & $(-2.78)$ & $(-1.78)$ & $(-1.95)$ & $(-4.66)$ & $(-8.77)$ \\
\hline \multirow[t]{2}{*}{ LGS } & 0.02 * & 0.10 & 0.05 * & 0.31 & $<0.01$ & $<0.01$ \\
\hline & $(-4.04)$ & $(-2.16)$ & $(-2.95)$ & $(-0.81)$ & $(-5.45)$ & $(-8.44)$ \\
\hline s.e. of diff $=$ & \multicolumn{2}{|c|}{$(0.50)$} & \multicolumn{2}{|c|}{$(0.42)$} & \multicolumn{2}{|c|}{$(>10)$} \\
\hline
\end{tabular}

High-Low significant $(p<0.05)$

$=$ Average s.e. of difference High - Low within line. 
Table 5.

Proportions of piglet-minutes observed at different locations about the gilt during farrowing.

Logits are in parenthesis.

Line

Location

Head

Feet

Back

Vulva

Creep

Udder

DF

High $\quad 0.02$

0.12

0.02

0.02

0.03

0.56

(-3.84)

$(-1.96)$

$(-3.66)$

$(-3.85)$

$(-3.46)$

(0.25)

Low $\quad 0.01$

0.13

0.01

0.04

0.01

0.58

$(-4.37)$

$(-1.89)$

$(-4.53)$

$(-3.06)$

$(-4.48)$

(0.32)

LFC High 0.03

0.10

0.04

0.03

$<0.01$

0.51

$$
(-3.44)
$$

$(-2.15)$

$(-3.13)$

$(-2.15)$

$(-5.31)$

(0.05)

Low $\quad 0.04$

0.13

0.02

0.02

0.02

0.46

$(-3.15)$

$(-1.89)$

$(-3.69)$

$(-3.69)$

$(-3.84)$

$(-0.17)$

LGA High 0.02

0.09

0.04

0.02

0.02

0.65

$(-4.14)$

$(-2.37)$

$(-3.27)$

$(-3.85)$

(-3.84)

(0.60)

Low $\quad 0.03$

0.09

0.01

0.03

0.01

0.53

$(-3.59)$

$(-2.32)$

$(-4.23)$

$(-3.61)$

$(-5.05)$

0.12)

LGS High 0.02 *

0.11

$0.01^{*}$

0.02

$0.01^{*}$

0.60

$(-3.78)$

$(-2.10)$

$(-4.55)$

$(-4.06)$

$(-4.53)$

(0.42)

Low $\quad 0.01$

0.13

0.05

0.03

0.06

0.49

$(-5.03)$

$(-1.93)$

$(-3.02)$

$(-3.45)$

$(-2.83)$

$(-0.04)$

s.e. of diff $=$

$(0.54)$

$(0.46)$

$(0.63)$

$(0.38)$

$(0.63)$

$(0.37)$

High-Low significant $(\mathrm{P}<.05)$

$=$ Average s.e. of difference High - Low within line. 


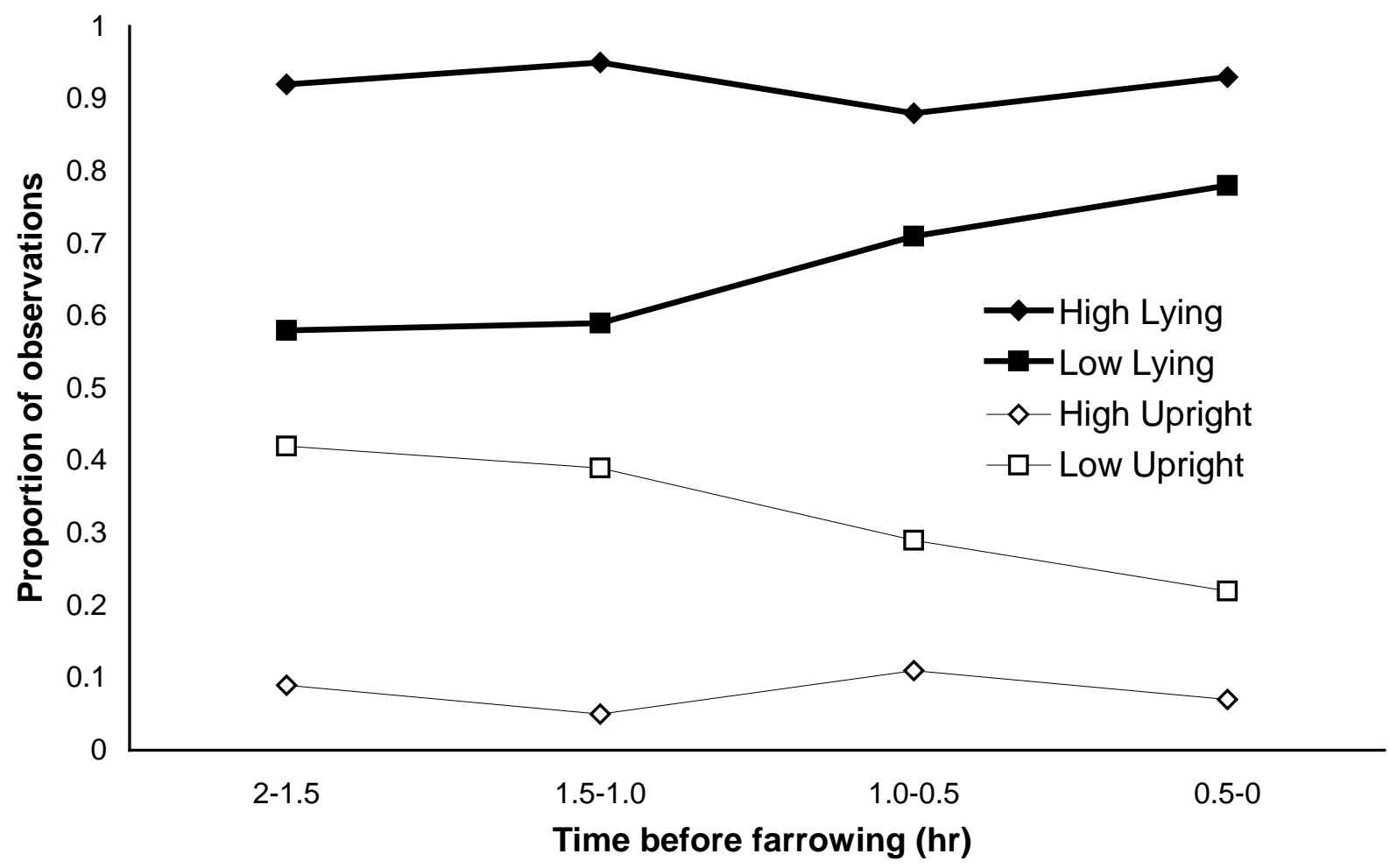

Fig.1. Changes in the proportion of high and low LGS line gilts adopting the lying (on side) and upright (stand, sit, belly lie) postures before farrowing. 


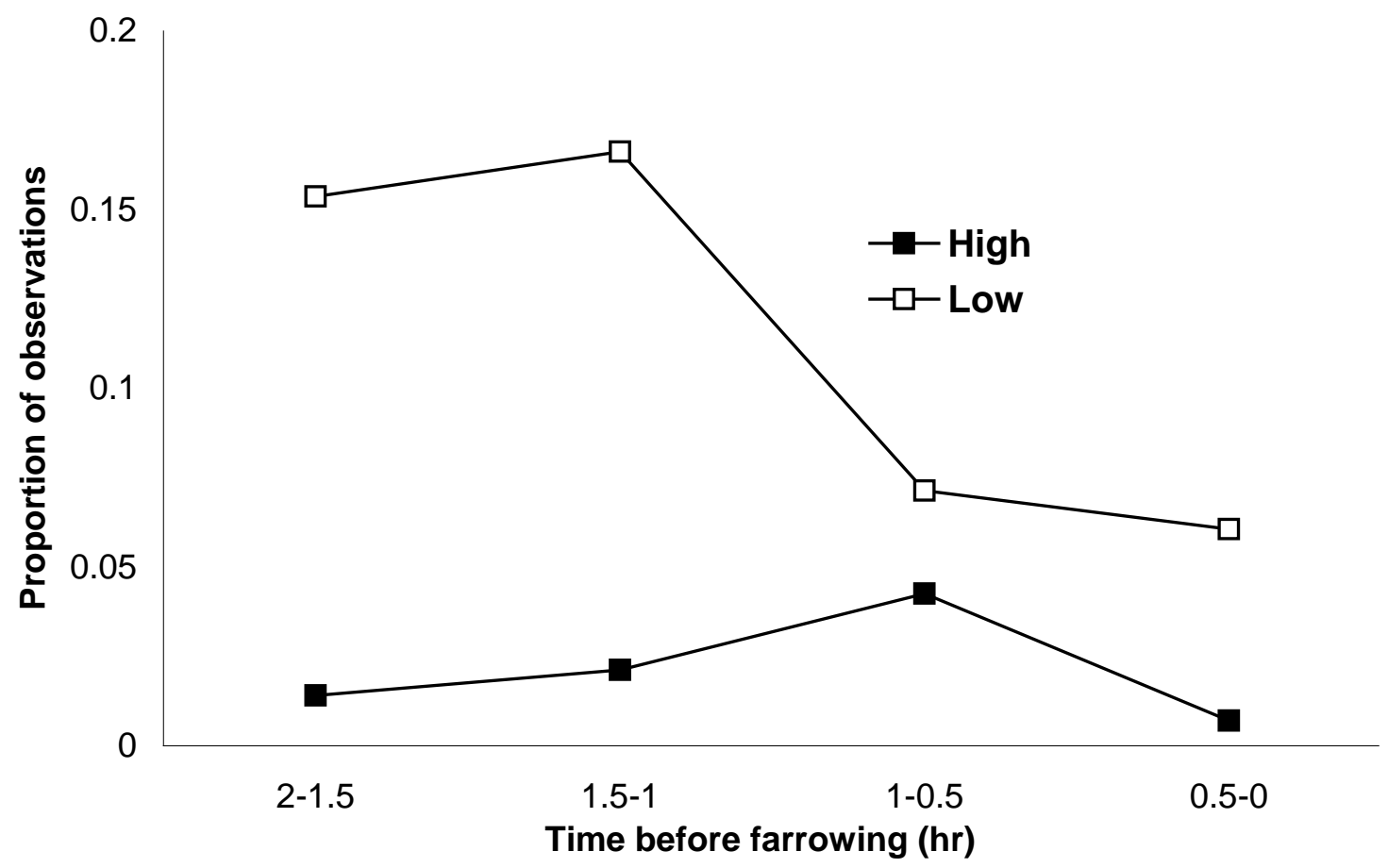

Fig.2. Changes in the proportion of high and low LGS line gilts exhibiting nesting behaviour before farrowing. 